\title{
Durability Assessment of Blended Concrete by Air Permeability
}

\author{
Dhruva Narayana Katpady ${ }^{1), *}$, Hirotaka Hazehara ${ }^{2)}$, Masashi Soeda ${ }^{2)}$, Takashi Kubota ${ }^{2)}$, and \\ Satoshi Murakami ${ }^{2}$
}

(Received December 13, 2016, Accepted February 6, 2018)

\begin{abstract}
Assessment of concrete cover quality is necessary for proper maintenance of concrete structures. Concrete durability is evaluated primarily based on chloride penetrability, neutralization and other external factors. The present study attempts to analyze concrete quality and its mass transfer resistance performance by measuring the air permeability and its relation with concrete durability indicators like chloride diffusion and neutralization. The applicability of air permeability as a durability indicator is validated using concrete with different materials, parameters and curing conditions. The tests are conducted on laboratory prepared concrete as well as for concrete exposed to actual marine conditions. From the experimental results, it is found that air permeability coefficient, neutralization coefficient and chloride ion diffusion coefficient have high correlation. It is suggested that air permeability could be considered as an alternative to estimate mass transfer resistance of concrete and as a concrete durability indicator.
\end{abstract}

Keywords: air permeability, concrete durability, neutralization, chloride diffusion, blended concrete, marine exposure, mass transfer resistance.

\section{Introduction}

Evaluation of concrete quality up to the depth of concrete cover is necessary for proper maintenance of reinforced concrete structures. One of the employed methods to analyze the existing concrete performance is the compressive strength. However, compressive strength alone cannot be an indicator for mass transfer resistance of concrete. Permeability of concrete is a major indicator of its performance in terms of durability. Carbon dioxide, chloride ion and water ingress are the primary cause of detrimental effects in concrete. Their penetration into concrete is governed by the pore structure. Hence air permeability and water permeability can be indicators for the magnitude of penetration of carbon dioxide or chloride ion. Air permeability is said to be highly correlated with porosity and pore size distribution of concrete and can be used as a measure of porosity and pore connectivity (Halamickova et al. 1995; Sugiyama et al. 1996; Abbas et al. 1999). Air permeability coefficient has high correlation with neutralization progress, water cement ratio, cement type and curing conditions (Basheer et al. 2001; Hui-sheng et al. 2009; Hamami et al. 2012).

Studies on air permeability and its relation to chloride diffusion are few and rather complicated. It is reported that

\footnotetext{
${ }^{1)}$ Department of Ocean Civil Engineering, Kagoshima University, 1-21-40, Korimoto, Kagoshima, Japan 8900065 .

*Corresponding Author; E-mail: drunarkat@gmail.com

${ }^{2)}$ Department of Civil Engineering, Fukuoka University, 8-19-1, Nanakuma, Jonan-ku, Fukuoka, Japan 814-0180.
}

Copyright $\odot$ The Author(s) 2018 chloride ion diffusion coefficient has a possibility of greatly varying between salt immersion test and in actual concrete structure. Due to such variations, evaluation of penetration of chloride ion into actual concrete structure should be considered for safer structures (Yamaji 2014). Diffusion coefficient is time dependent and decreases over time (Halamickova et al. 1995; Luping and Gulikers 2007; Pack et al. 2010; Al-alaily and Hassan 2016). This makes it difficult to evaluate chloride ion penetration into concrete by various methods. However, long-term resistance to chloride ion penetration is unclear. Since, supplementary cementitious materials like fly ash and Portland blast furnace cement are excellent in resistance to chloride ion penetration (Osborne 1999; Thomas and Bamforth 1999; McCarthy and Dhir 2005; Berndt 2009), studies on their relation between air permeability and chloride diffusion is important.

In case of air permeability, factors affecting measurement are pore structure and moisture content in concrete. On the other hand, it is considered that penetration of chloride ion into concrete is governed by the capillary absorption, permeability and diffusion by concentration gradient depending on several factors and each has its own testing methods (Basheer et al. 2001). In the electrophoretic test method (chloride ion migration test) for evaluation of chloride ion penetration, concrete specimen is subjected to water saturated condition. The main factor affecting the chloride ion diffusion coefficient by electrophoretic test (here-in-after referred as “ $\mathrm{D}_{\mathrm{e}}$ ") is hence the pore structure in concrete (Halamickova et al. 1995; Papadakis 2000; Yang 2006; Saeki et al. 2006) without any effect of the capillarity and permeability. Hence, air permeability coefficient can be possibly used to evaluate $\mathrm{D}_{\mathrm{e}}$. Also, assessment of chloride 
diffusion by electrophoretic test has its own drawbacks owing to complexity and time consumption (Truc et al. 2000) and it often overestimates the diffusion value (Luping and Gulikers 2007). But a high correlation of air permeability with $D_{e}$ provides a scope for indirect estimation of apparent diffusion coefficient by salt immersion test (herein-after referred as " $\mathrm{D}_{\mathrm{a}}$ ")

All the facts put together, present study aims at evaluating mass transfer resistance performance of concrete by measurement of air permeability. The correlation between air permeability and other durability indicators were examined for possible application of air permeability as a durability indicator on a wide range of conditions. Since $D_{a}$ can be estimated from $D_{e}$ using established equations, a good correlation between air permeability and $D_{e}$ facilitates easy estimation of $\mathrm{D}_{\mathrm{a}}$. Hence, the study aims to find the correlation between air permeability and $\mathrm{D}_{\mathrm{e}}$. This provides an indirect estimation of chloride diffusion coefficient by air permeability. The relation between air permeability and neutralization, chloride diffusion by salt immersion test, porosity, cement types and curing conditions have been studied extensively. However, there are no substantial reports on correlation between air permeability and chloride diffusion coefficient by electrophoretic test especially for both laboratory tests and actual marine structures.

Laboratory tests to determine neutralization coefficient, chloride diffusion coefficient by electrophoretic test of chloride ion $\left(\mathrm{D}_{\mathrm{e}}\right)$, apparent diffusion coefficient by salt immersion test $\left(\mathrm{D}_{\mathrm{a}}\right)$ and air permeability were employed. Concrete structure at sea condition for 23 years made by using fly ash and Portland blast furnace cement were also examined for penetration of chloride ion. The relation between air permeability and chloride diffusion in concrete exposed to marine conditions was also analyzed. In particular, measurement of $\mathrm{D}_{\mathrm{a}}$ and $\mathrm{D}_{\mathrm{e}}$ in actual marine environment, at deeper sections of concrete cores where chloride ions not penetrated was also performed.

\section{Materials and Method}

Broadly, experimental investigations were carried out for laboratory prepared concrete and concrete cores obtained from concrete structure exposed to actual marine conditions for as long as 23 years. The experimental procedure for each is explained.

\subsection{Laboratory Prepared Concrete}

Three types of concrete were prepared with Ordinary Portland cement ("N"), type B-blast furnace slag cement ("BFSC") and fly ash as admixture (cement replacement). The properties of materials used are shown in Table 1. Three water to binder ratios (“W/B"), 45, 55, 65\% were employed (Table 2, all materials in $\mathrm{kg} / \mathrm{m}^{3}$ ). OPC, FAC and BBC are concretes made with Ordinary Portland cement ("N"), type B-blast furnace slag cement ("BFSC") and fly ash as admixture. Replacement ratio of fly ash in FAC was $20 \%$ for all W/B. Crushed stone with nominal maximum size of
$20 \mathrm{~mm}$ was used as coarse aggregate and sea sand as fine aggregate. Ratio of fine aggregate to total aggregate content (" $\mathrm{S} /(\mathrm{S}+\mathrm{G})$ ") is varied to adjust the slump of all concrete types to designed slump of $8 \pm 1 \mathrm{~cm}$.

\subsubsection{Casting and Curing}

Cylindrical specimens were prepared with varied dimensions for each set of test $(\varphi 7.5 \times 15 \mathrm{~cm}$ cylindrical specimens for compressive strength test, $\varphi 10 \times 15 \mathrm{~cm}$ cylindrical specimens for air permeability and electrophoretic test, $\varphi 7.5 \times 15 \mathrm{~cm}$ cylindrical specimens for accelerated neutralization test and $\varphi 10 \times 10 \mathrm{~cm}$ cylindrical specimens for salt immersion test).

All concrete specimens were either water cured or atmosphere (Air curing) cured with relative humidity of $60 \%$ and $20{ }^{\circ} \mathrm{C}$ for 28 days.

\subsubsection{Compressive Strength Test}

Compressive strength test of cylindrical specimens of $\varphi 7.5 \times 15 \mathrm{~cm}$, water and atmosphere cured for 28 days were carried out in accordance with JIS A 1108. Average of three samples was taken for compressive strength (MPa: megapascal).

\subsubsection{Air Permeability Test}

Cylindrical specimens of $\varphi 10 \times 15 \mathrm{~cm}$ were used prior to electrophoretic test. All specimens both water and atmosphere cured were further dried for a period of 7 days at relative humidity of $60 \%$ and $20{ }^{\circ} \mathrm{C}$ until no reduction in mass. The variation of air permeability result with different relative humidity was experimented and reported by Care and Derkx (2011) and Villani et al. (2014). However, in this study, this condition was adopted to match the conditions of laboratory during the air permeability experiment. The sides of specimens were coated with epoxy and taped with aluminum, except top and bottom surface to promote air flow into specimen. Compressed air was introduced into the chamber. When the amount of permeated air became constant, the amount of air permeation was measured by the water substitution method (Fig. 1). The air permeability coefficient or air permeability was calculated by Eq (1) (RILEM TC 116-PCD - permeability of concrete as criterion of its durability). Where, $\mathrm{P}_{1}=1.6 \mathrm{kgf} / \mathrm{cm}^{2}$, $\mathrm{P}_{2}=1.0332 \mathrm{kgf} / \mathrm{cm}^{2}, \mathrm{r}=1.025 \times 10^{-6} \mathrm{~kg} / \mathrm{cm}^{3}$.

$$
K=\frac{2 h P_{2} r}{P_{1}^{2} P_{2}^{2}} \times \frac{Q}{A}
$$

where, K: air permeability coefficient $(\mathrm{cm} / \mathrm{s}), \mathrm{P}_{1}$ : Load pressure $\left(\mathrm{kgf} / \mathrm{cm}^{2}\right), \mathrm{P}_{2}$ : Barometric pressure $\left(\mathrm{kgf} / \mathrm{cm}^{2}\right), \mathrm{h}$ : Thickness of specimen $(\mathrm{cm}), \mathrm{Q}$ : Volume of air permeated $\left(\mathrm{cm}^{3} / \mathrm{s}\right)$, A: Area of air permeated $\left(\mathrm{cm}^{2}\right), \mathrm{r}$ : mass per unit volume of air $\left(\mathrm{kg} / \mathrm{cm}^{3}\right), \mathrm{cm}$ : centimeter $=10^{-2} \mathrm{~m}$, $\mathrm{kgf}$ : kilogram-force $=9.81 \mathrm{~N}, \mathrm{~cm}^{2}=10^{-4} \mathrm{~m}^{2}, \mathrm{~cm}^{3}=10^{-6} \mathrm{~m}^{2}$.

\subsubsection{Accelerated Neutralization Test}

Cylindrical specimens of $\varphi 7.5 \times 15 \mathrm{~cm}$ both water and atmosphere cured for 28 days were epoxy coated except test 
Table 1 Physical properties of materials used.

\begin{tabular}{|c|c|c|}
\hline Abbreviation & Employed material & Physical properties \\
\hline \multirow[t]{2}{*}{$\mathrm{C}$} & \multirow[t]{2}{*}{ Ordinary Portland cement } & Specific gravity $=3.16$ \\
\hline & & Specific surface area $=3280 \mathrm{~cm}^{2} / \mathrm{g}$ \\
\hline \multirow[t]{2}{*}{ BFSC } & \multirow[t]{2}{*}{ Blast furnace slag cement } & Specific gravity $=3.04$ \\
\hline & & Specific surface area $=3870 \mathrm{~cm}^{2} / \mathrm{g}$ \\
\hline \multirow[t]{2}{*}{ Fly Ash } & \multirow[t]{2}{*}{ Fly ash } & Specific gravity $=2.34$ \\
\hline & & Specific surface area $=3960 \mathrm{~cm}^{2} / \mathrm{g}$ \\
\hline \multirow[t]{2}{*}{$\mathrm{S}$} & \multirow[t]{2}{*}{ Fine aggregate } & Specific gravity $=2.58$ \\
\hline & & Water absorption $=1.61 \%$ \\
\hline \multirow[t]{2}{*}{ G } & \multirow[t]{2}{*}{ Coarse aggregate } & Specific gravity $=2.67$ \\
\hline & & Water absorption $=1.14 \%$ \\
\hline AEW & \multicolumn{2}{|c|}{ Air entraining water reducing agent, JIS A 6204 , standard form } \\
\hline $\mathrm{AE}$ & \multicolumn{2}{|c|}{ Air entraining agent JIS A 6201, standard form } \\
\hline
\end{tabular}

Table 2 Mix proportion of laboratory prepared concrete.

\begin{tabular}{|c|c|c|c|c|c|c|c|c|c|c|c|c|}
\hline & W/B (\%) & $\mathrm{S} /(\mathrm{S}+\mathrm{G})$ & $\mathrm{W}$ & $\mathrm{C}$ & BFSC & Fly Ash & $\mathrm{S}$ & $\mathrm{G}$ & \multirow[t]{2}{*}{$\mathrm{AE}(\%)$} & \multirow[t]{2}{*}{ AEW (\%) } & \multirow{2}{*}{$\begin{array}{c}\text { Slump } \\
(\mathrm{cm})\end{array}$} & \multirow[t]{2}{*}{ Air $(\%)$} \\
\hline & & $(\%)$ & \multicolumn{6}{|c|}{ Materials $\left(\mathrm{kg} / \mathrm{m}^{3}\right)$} & & & & \\
\hline \multirow[t]{3}{*}{$\mathrm{OPC}$} & 45 & 44 & \multirow{6}{*}{165} & 366 & - & - & 765 & 1007 & 0.015 & 0.004 & 8 & 3.5 \\
\hline & 55 & 46 & & 300 & - & - & 825 & 995 & 0.016 & 0.004 & 8.5 & 4 \\
\hline & 65 & 48 & & 255 & - & - & 877 & 984 & 0.015 & 0.004 & 8 & 3.5 \\
\hline \multirow[t]{3}{*}{$\mathrm{BBC}$} & 45 & 44 & & - & 366 & - & 765 & 1007 & 0.015 & 0.004 & 8 & 4 \\
\hline & 55 & 46 & & - & 300 & - & 826 & 1003 & 0.015 & 0.004 & 8 & 5 \\
\hline & 65 & 48 & & - & 255 & - & 880 & 987 & 0.017 & 0.004 & 7 & 4 \\
\hline \multirow[t]{3}{*}{ FAC } & 45 & 38 & 160 & 284 & - & 71 & 666 & 1125 & 0.013 & 0.052 & 8 & 4 \\
\hline & 55 & 40 & 162 & 233 & - & 59 & 721 & 1112 & 0.012 & 0.038 & 9 & 3.5 \\
\hline & 65 & 44 & 162 & 199 & - & 50 & 810 & 1067 & 0.013 & 0.038 & 7 & 3.5 \\
\hline
\end{tabular}

surface to promote $\mathrm{pH}$ neutralization (henceforth referred as "neutralization") under $\mathrm{CO}_{2}$ concentration of 5\%, temperature of $20 \pm 2{ }^{\circ} \mathrm{C}$ and relative humidity of $60 \%$ as per JIS A 1153. At predetermined promotion periods of $30,60,90$, 120, 150 days specimens were cut open to measure the neutralization depth by phenolphthalein spray method. Neutralization coefficient $(\mathrm{mm} / \sqrt{ }$ year, $\mathrm{mm}$ : millimeter $=10^{-3} \mathrm{~m}$ ) was also calculated using simple equation based on Fick's first law.

\subsubsection{Salt Immersion Test}

Salt immersion test and determination of diffusion coefficient were done according to JIS A 1154 and JSCE-G572 respectively for specimens both water and atmosphere cured. Cylindrical specimens of $\varphi 10 \mathrm{~cm} \times 10 \mathrm{~cm}$ were used for salt immersion test. The side and bottom surface were coated with epoxy, except top surface for the test after which specimens were immersed in $10 \%$ concentration of $\mathrm{NaCl}$ solution for 91 days. Specimens were drilled from the test surface to collect powder for every $5 \mathrm{~mm}$ thickness interval up to $40 \mathrm{~mm}$. Total chloride ion content was determined and diffusion coefficient, $D_{a}\left(\mathrm{~cm}^{2} /\right.$ year, $\left.\mathrm{cm}^{2}=10^{-4} \mathrm{~m}^{2}\right)$ was calculated up to a depth of $10 \mathrm{~mm}$ using Fick's second law of diffusion.

\subsubsection{Electrophoretic Test of Chloride Ion}

Cylindrical specimens of $\varphi 10 \mathrm{~cm} \times 5 \mathrm{~cm}$ were used after air permeability test. These specimens were coated with epoxy on the sides except opposite surfaces. And, chloride ion diffusion coefficient, $\mathrm{D}_{\mathrm{e}}\left(\mathrm{cm}^{2} /\right.$ year, $\left.\mathrm{cm}^{2}=10^{-4} \mathrm{~m}^{2}\right)$ was determined in accordance with JSCE-G571. 

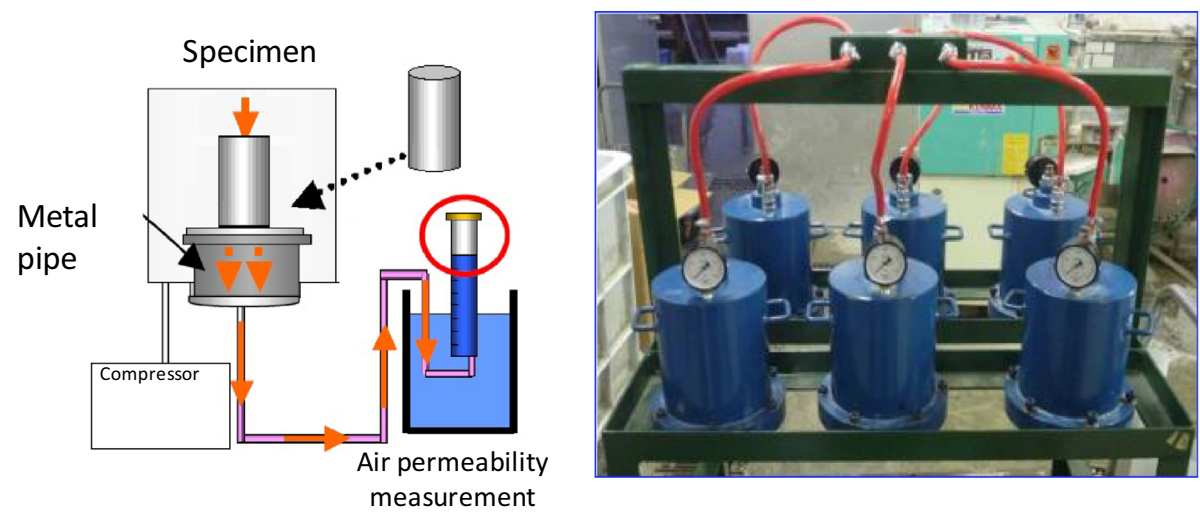

Fig. 1 Air permeability test setup.

\subsubsection{Porosity}

Mercury intrusion porosimetry was employed to determine the pore size distribution of each concrete. Pore sizes are represented in nanometers $\left(\mathrm{nm}=10^{-9} \mathrm{~m}\right)$.

\subsection{Concrete Cores Obtained from Concrete Structure Exposed to Marine Conditions}

In this experiment, concrete cores of actual structure in marine environment were used as specimens. The 23-yearold concrete structures were constructed using B type Portland blast furnace cement and partial replacement of cement by fly ash. For concrete with type-B blast furnace cement (here-in-after referred as "BB") W/B was $65 \%$ and compressive strengths of 31.3 and $28.9 \mathrm{MPa}$ at splash zone and tidal zone area, respectively. On the other hand, in case of concrete with fly ash partially replacing cement (here-inafter referred as "FA"), W/B was 45 , and $30 \%$ replacement with fly ash. Compressive strength was $39.6 \mathrm{MPa}$ and 41.2 $\mathrm{MPa}$ in splash and tidal zone, respectively.

Cores of $\varphi 9 \mathrm{~cm} \times 20 \mathrm{~cm}$ were extracted from exposed concrete structure at tidal and splash zones. Tests were carried out by using cut slices of the concrete core as shown in Fig. 2. Measurement of penetrated chloride ion was carried out in accordance with JIS A 1154. Slices of $1 \mathrm{~cm}$ were taken up to depth of $5 \mathrm{~cm}$ to obtain chloride content profile along the depth of concrete. The chloride diffusion coefficient then determined for top portion of concrete exposed to sea is represented as " $\mathrm{D}_{\mathrm{c}}$ ". Area of concrete without chloride ion content (not directly exposed to sea, bottom $10 \mathrm{~cm}$ portion) was used for air permeability test, salt immersion test and electrophoretic test of chloride ion. Air permeability, salt immersion, electrophoretic test and porosity tests were carried out similar to the procedures explained in Sect. 2.1. Salt immersion test was done for a period of 200 days.

\section{Results and Discussion}

\subsection{Laboratory Prepared Concrete}

\subsubsection{Relationship Between Air Permeability,} Water Binder Ratio and Compressive Strength

The relationship between air permeability and water binder ratio of concretes are shown in Fig. 3. The difference in curing conditions is also projected in the graphs. Regardless of cement types used, air permeability is lesser for water cured specimens than atmosphere cured similar to other findings ( $\mathrm{Mu}$ et al. 2015). Water cured OPC concrete is found to have lesser permeability at lower W/B compared to $\mathrm{FAC}$ and $\mathrm{BBC}$ and higher as the $\mathrm{W} / \mathrm{B}$ increases. Atmosphere cured $\mathrm{BBC}$ and FAC show higher permeability. The difference in permeability between curing conditions of $\mathrm{BBC}$ and FAC for same W/B tend to increase compared to OPC. Figure 4 shows the relationship between the compressive strength and permeability coefficient after 28 days of concrete curing.

Permeability coefficient in any cement types, decreases with increase in compression strength regardless of curing conditions. Relationship with the air permeability coefficient and the compressive strength showed high correlation with $\mathrm{R}^{2}=0.9587$ for $\mathrm{OPC}, \mathrm{R}^{2}=0.9289$ for $\mathrm{BBC}$ and $\mathrm{R}^{2}=0.9261$ for FAC. However, FAC and BBC show lesser correlation than OPC suggesting the effect of curing conditions which showed large differences in permeability for different curing conditions for FAC and BBC. Hence blended concrete requires water curing for longer curing periods.

\subsubsection{Relation Between Air Permeability, Neutralization Coefficient and Compressive Strength}

Figure 5 shows the relationship between the neutralization coefficient and air permeability. Neutralization coefficient increases for any cement type with increase in $\mathrm{W} / \mathrm{B}$, and with increase in air permeability (Basheer et al. 2001; Khunthongkeaw et al. 2006; Neves et al. 2015), which

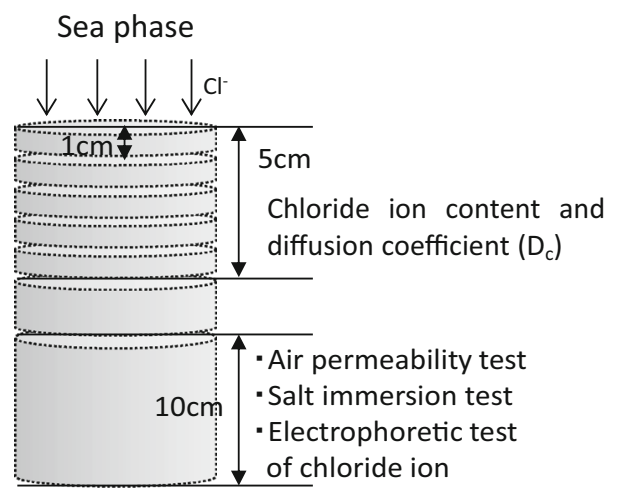

Fig. 2 Exposed concrete core. 


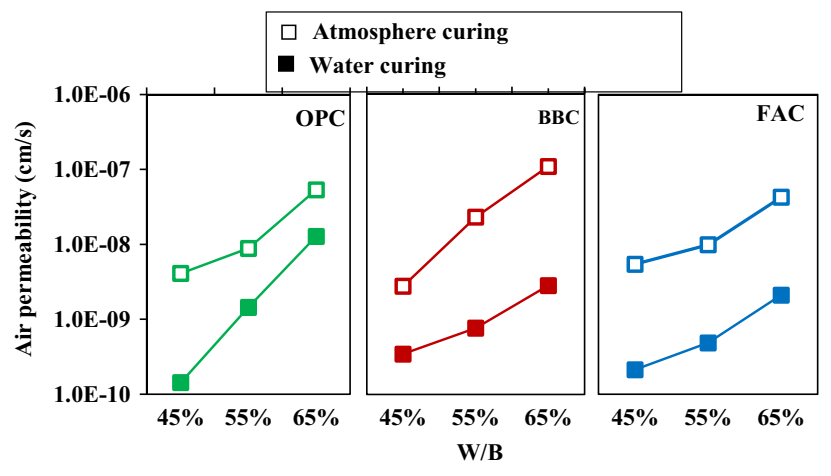

Fig. 3 Air permeability versus water binder ratio.

means W/B, air permeability, neutralization coefficient and compressive strength are all highly correlated (Sanjuan and Munoz-Martialay 1996; Hui-sheng et al. 2009; Neves et al. 2015; Salvoldi et al. 2015). Between cement types, for same $\mathrm{W} / \mathrm{B}$, curing condition and air permeability, OPC shows less neutralization compared to $\mathrm{BBC}$ and FAC similar to the findings of (Bijen 1996; Khunthongkeaw et al. 2006). OPC has relatively higher content of cement and hence produces higher amounts of calcium hydroxide. This is thought to be the cause for reduced neutralization. Higher the compression strength lower is the neutralization coefficient for OPC, $\mathrm{BBC}$, and FAC but showing varied correlation with different curing conditions (Fig. 6, shows relationship between compressive strength and neutralization coefficient).

By comparing the relationship between air permeability coefficient and the neutralization coefficients shown in Fig. 5, neutralization coefficient is highly correlated with the compression strength for all types of cement which is in line with other studies (Al-Amoudi et al. 2009; Guiglia and Taliano 2010; Neves et al. 2015). But those studies showed rather less correlation between air permeability and neutralization suggesting that estimation would be better considering compressive strength. Since in the present study air permeability, compressive strength and neutralization all show high correlation, it is suggested that estimation of neutralization rate by air permeability coefficient can be done by taking into account the W/B, cement types and

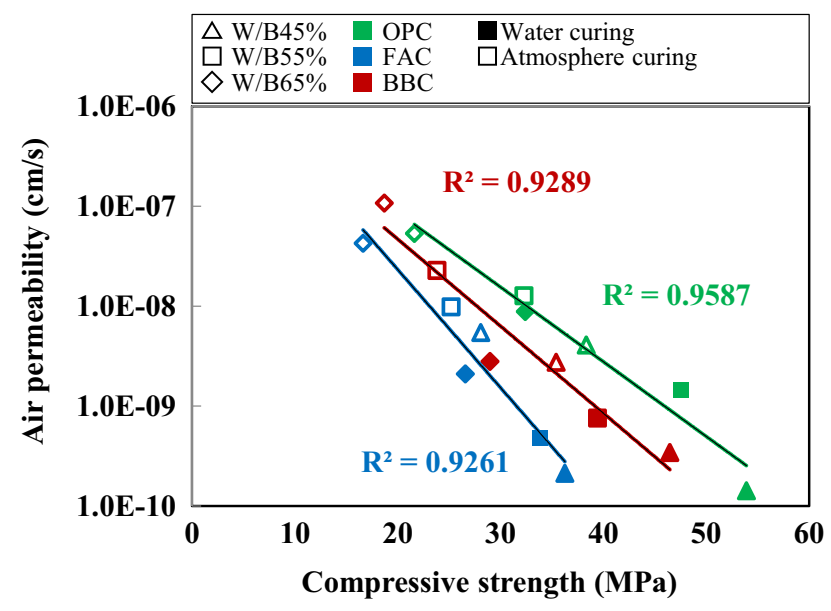

Fig. 4 Air permeability versus compressive strength. curing conditions. But $\mathrm{BBC}$ is not much affected by W/B as compared to others. A similar argument is made by Huisheng et al. (2009).

\subsubsection{Chloride Penetration and Air Permeability}

Corresponding to decrease in air permeability coefficient in any of the cement type, $D_{a}$ decreases (Fig. 7, shows relationship between air permeability and chloride diffusion coefficient by salt immersion test, “ $\mathrm{D}_{\mathrm{a}}$ ”). Fairly good correlation is found between diffusion coefficient and air permeability for all cement types. According to Sugiyama et al. (1996), correlation exists in the range where water cement ratio significantly effects air permeability. As in Fig. 7, water cured specimens show low diffusion coefficient than atmosphere cured. According to Ramezanianpour and Malhotra (1995) and Guneyisi et al. (2009), lack of moist curing significantly lowers concrete resistance to chloride penetration and even more in blended cements, similar to results found in the present study. Especially, BBC and FAC show very low diffusion coefficient (Bijen 1996; Leng et al. 2000), but in the present case even when atmosphere cured. Concrete with slag shows superior resistance to chloride penetration (Yildirim et al. 2011). Cement type, W/B and curing condition are very influential factors concerning chloride penetration (Song et al. 2008; Guneyisi et al. 2009; Yildirim et al. 2011). For low W/B, even though air permeability differs largely between curing conditions, $D_{a}$ show less difference. Atmosphere cured concretes show greater variation in air permeability and $\mathrm{D}_{\mathrm{a}}$ for all $\mathrm{W} / \mathrm{B}$ than water cured concretes suggesting that the pore structure can alter the chloride transport in concrete. Hence from the observations, it can be understood that chloride penetration is much strongly governed by chemical processes (ion transfer and physical adsorption by charge interaction, concentration gradient, and immobilization) rather than physical processes (advection) alone. From the observations, when estimating the chloride ion apparent diffusion coefficient by permeability coefficient, it is necessary to take into account at least the cement type and curing conditions.

Figure 8 shows the relationship between the effective chloride diffusion coefficient, $\mathrm{D}_{\mathrm{e}}$, determined by electrophoretic test and permeability coefficient. Within the scope of the results shown in Fig. 8, regardless of cement type, those subjected to water curing, show fairly high correlation between the permeability coefficient and $D_{e}$, but for atmosphere cured concrete, the correlation with cement type is less. In the case of atmosphere cured concrete subjected to vacuum during air permeability test and later saturated when subjected to electrophoretic test changes the internal conditions of concrete; from dry concrete including unreacted cement to saturated concrete with possible rehydration reaction. This results in varied air permeability results before and after the tests. Hence, this is thought to be one of the reasons for low correlation for atmosphere cured concrete. The degree of saturation highly effects chloride diffusion (Nielsen and Geiker 2003). Overall result shows lower permeability for water cured specimens than atmosphere cured (Care and Derkx 2011). The possibility of estimating 


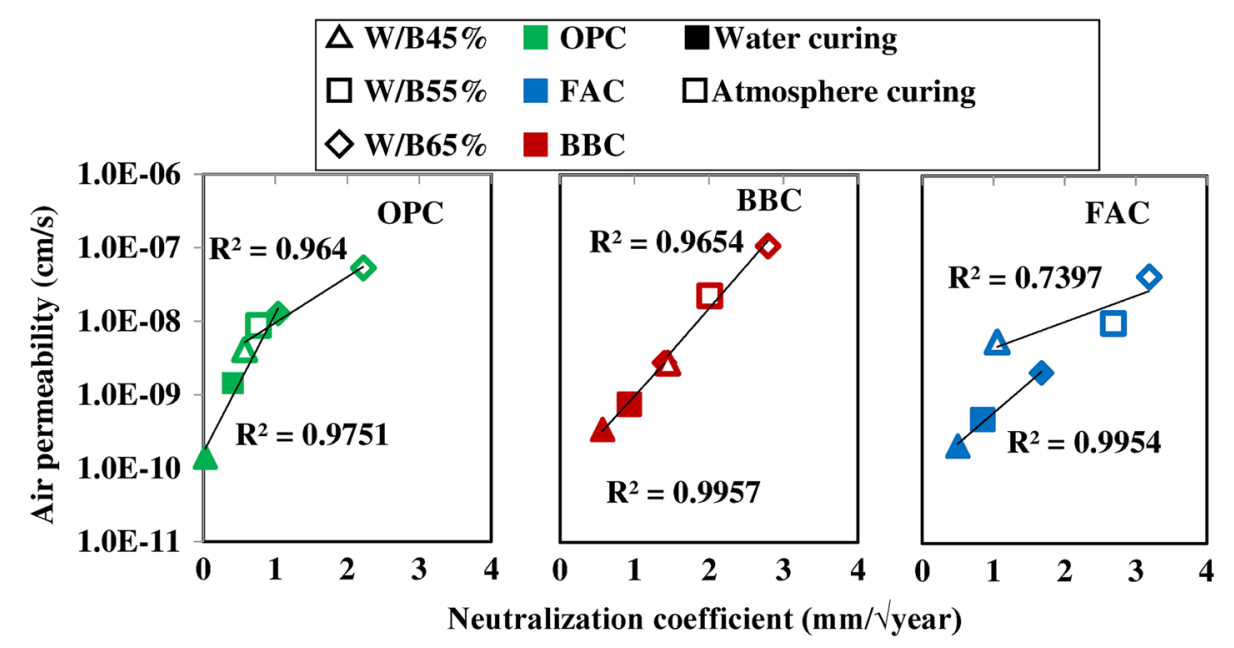

Fig. 5 Air permeability versus neutralization coefficient.

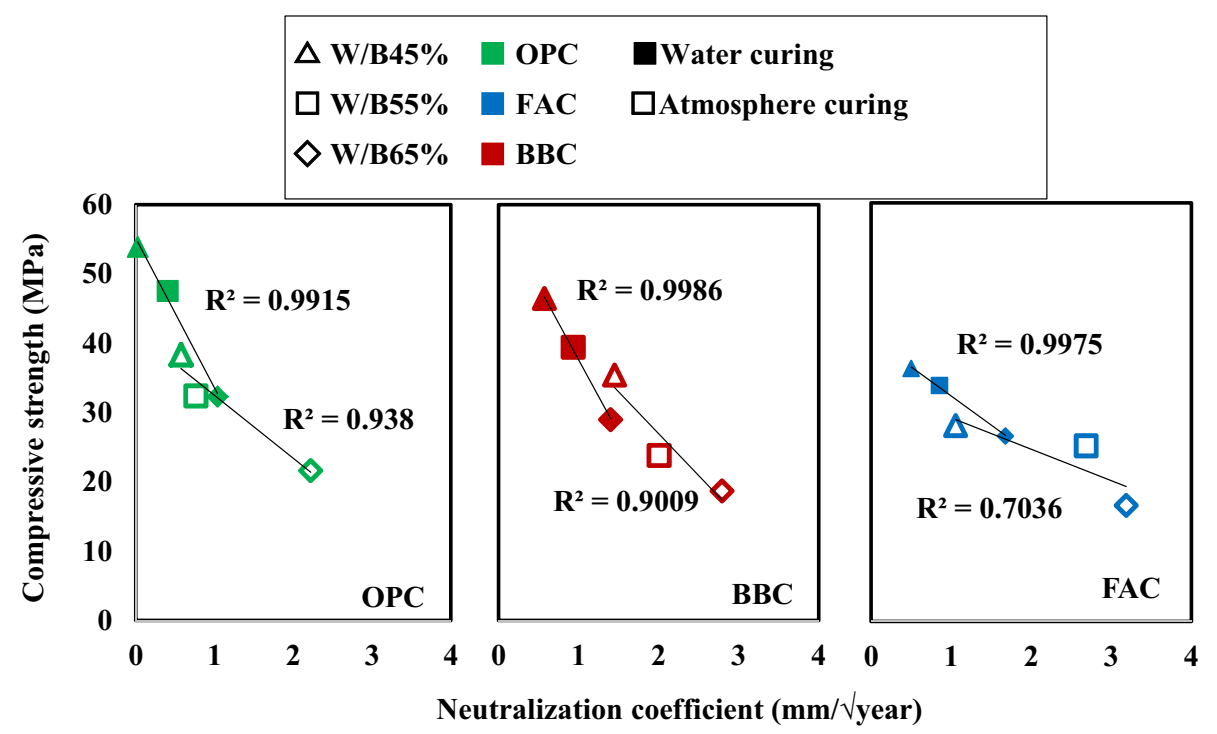

Fig. 6 Compressive strength versus neutralization coefficient.

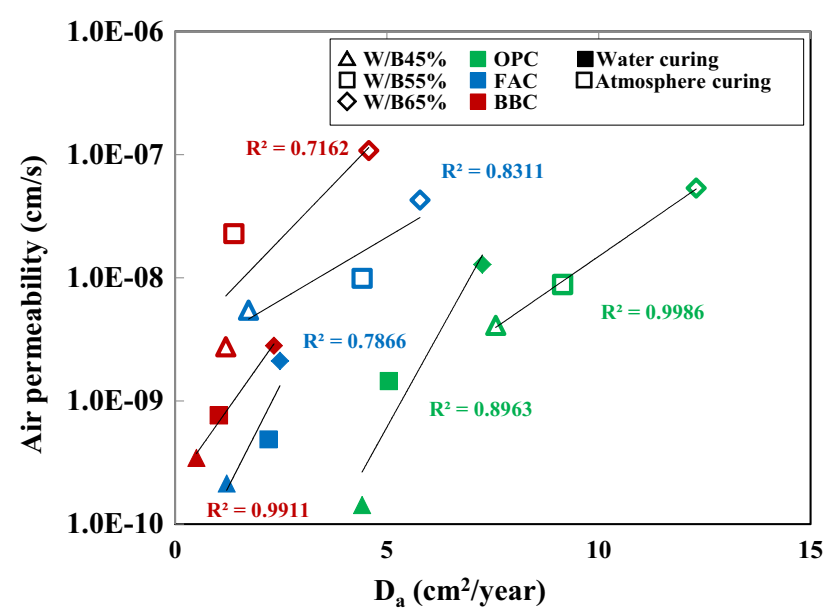

Fig. 7 Air permeability versus apparent chloride diffusion coefficient by salt immersion test.

$\mathrm{D}_{\mathrm{e}}$ without considering cement types by permeability coefficient can be considered but moisture condition and curing International Journal of Concrete Structures and Materials

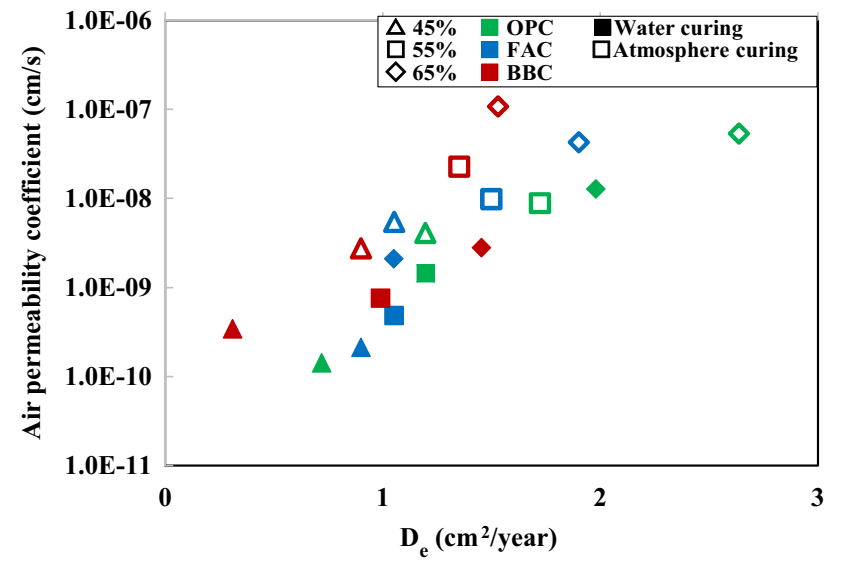

Fig. 8 Air permeability versus effective chloride diffusion coefficient by electrophoretic test.

are accountable. However, further investigation is recommended to clearly understand the correlation and possible estimation by air permeability. 


\subsection{Exposed Concrete to Actual Marine Conditions}

Figure 9 shows the relationship between the air permeability coefficient, chloride diffusion coefficient $\left(D_{c}\right)$ of exposed concrete core (up to $5 \mathrm{~cm}$ from surface depicted in Fig. 2), and chloride diffusion coefficient $\left(D_{a}\right)$ by salt immersion test for 200 days of bottom part not affected by chloride. In the figure, "BB splash" means upper part of concrete core up to $5 \mathrm{~cm}$ which was exposed to marine condition and "BB splash 200" means bottom part of concrete core subjected to salt immersion test for 200 days. Correlation between air permeability and $\mathrm{D}_{\mathrm{c}}$ is not confirmed in the case of exposed part but higher degree of correlation for $\mathrm{D}_{\mathrm{a}}$ by salt immersion test for 200 days. The difference in apparent diffusion coefficient between sea condition and immersion test is due to time dependent declination of diffusion coefficient due to the long-term hydration reaction of cement or blended cements (Takewaka and Matsumoto 1988; Costa and Appleton 1999). However, there are several other factors to be considered for marine exposed concrete. This makes it more complicated to arrive at relationship between permeability and chloride penetration. Figure 10 shows the relationship between the air permeability and $D_{e}$. $\mathrm{D}_{\mathrm{e}}$ seems to be higher for higher air permeability in any concrete. Although the measured points are few, it is suggested that air permeability coefficient and $\mathrm{D}_{\mathrm{e}}$ have significant correlation, unlike $D_{a}$ or $D_{c}$. Sharif et al. (1997) and Tegguer et al. (2013) also showed a highly correlated linear relationship between chloride diffusion and air permeability (Sharif et al. 1997; Tegguer et al. 2013). These findings show that air permeability can be an alternative to chloride diffusion obtained by electrophoretic test.

Specimens which were water cured showed high correlation regardless of cement types and water cement ratio in Fig. 8. And, this relationship differs from Fig. 10 due to the influence of water content ratio in concrete. Incidentally, water content ratio was $60 \%$ in exposed concrete core at sea condition, and $75 \%$ in prepared concrete when measuring air permeability. It is a well-known fact that air permeability is influenced by water content in concrete and that pre-conditioning is required which makes the test often sensitive

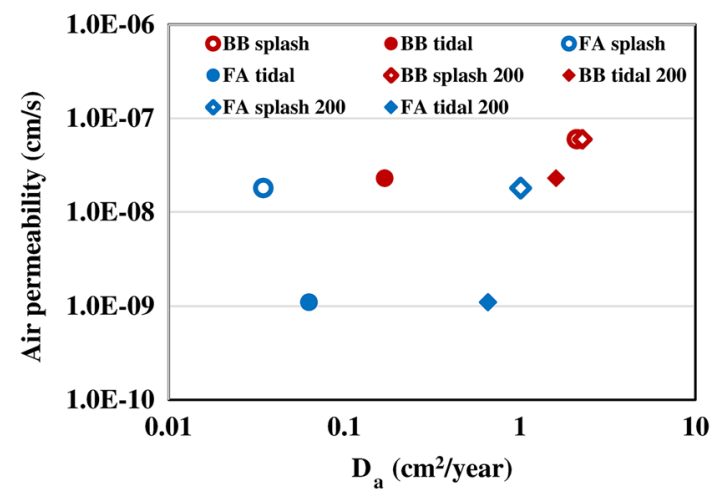

Fig. 9 Air permeability versus chloride diffusion coefficient by salt immersion test $\left(D_{a}\right)$ and chloride diffusion coefficient of marine exposed concrete $\left(D_{c}\right)$ for exposed concrete.
(Zaharieva et al. 2003). The difference in slope of correlation between Figs. 8 and 10 is assumed to be the effect of difference in water content rate when measured. In case of laboratory prepared atmosphere cured concrete, low correlation was observed between air permeability and $D_{e}$ due to the changes in pore structure of concrete when concrete is transferred from air permeability test to electrophoretic test because of possible rehydration reaction of cement in the process of electrophoretic test of chloride ion and saturated water processing.

The results of air permeability depend on degree of saturation of specimen under test and how it is dried (Sugiyama et al. 1996). Hence, estimation of $D_{e}$ by air permeability for laboratory prepared concrete and actual structure exposed to marine conditions is possible by considering the effect of water content ratio. From these results, $D_{e}$ can be estimated by measurement of air permeability regardless of cement type or concrete properties, but water content should be considered.

Effects of pore structure on diffusion coefficient of BBC and FAC in existing structure is evaluated as a relationship between volume of pores for a range of pore diameter and respective diffusion coefficients by linear approximation method depicting correlation coefficient $\mathrm{R}^{2}$.

The diffusion coefficient of all concretes combined versus pore volume of respective concrete for a particular range of pore size (say 200-500 nm marked as vertical block in Fig. 11a) is plotted and $\mathrm{R}^{2}$ is determined as illustrated by Fig. 11. Similar procedure is followed for air permeability, $D_{a}, D_{e}$ versus pore volume for other pore size range (for ex; $50-100 \mathrm{~nm}, 500-1000 \mathrm{~nm}$ ) and $\mathrm{R}^{2}$ values are determined. The $\mathrm{R}^{2}$ values obtained for varied pore size ranges are then plotted as shown in Fig. 12. The $\mathrm{D}_{\mathrm{c}}$ of top portion of concrete core exposed to marine condition had the highest correlation coefficient for pore diameter range of 50-200 nm, and decreased with increasing pore size in concrete. On the other hand, $\mathrm{D}_{\mathrm{a}}$ of concrete core bottom portion subjected to immersion test had greatest correlation coefficient between pore diameters from 200 to $1000 \mathrm{~nm}$, confirming large effect of pore diameter in comparison with marine exposure. It is found that effect of pore diameter on penetration of chloride ion under various conditions is different. This is attributed to the fact that, penetration property

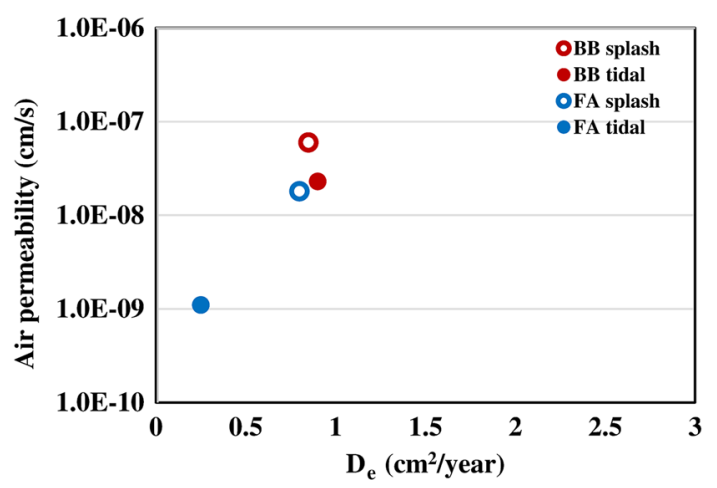

Fig. 10 Air permeability versus effective chloride diffusion coefficient $\left(D_{e}\right)$ for exposed concrete. 


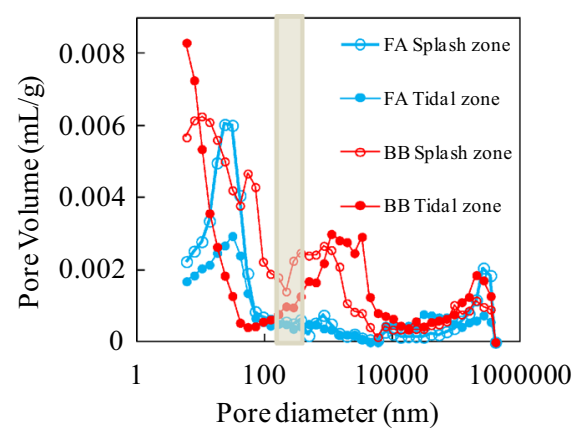

(a)

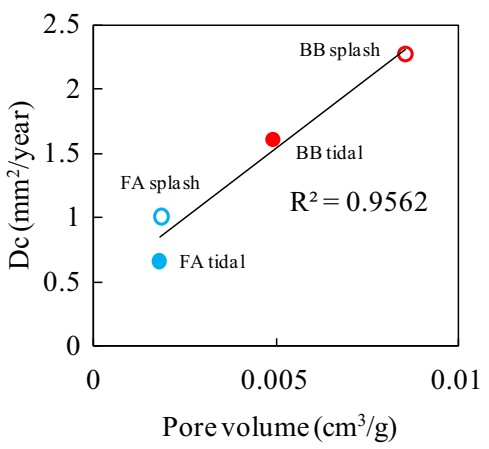

(b)

Fig. 11 An example showing the determination of $R^{2}$ between $D_{\mathrm{c}}$ and pore volume, a pore distribution of concretes exposed to marine conditions and $\mathbf{b} D_{c}$ versus pore volume for all concretes between pore size of $200-500 \mathrm{~nm}$.

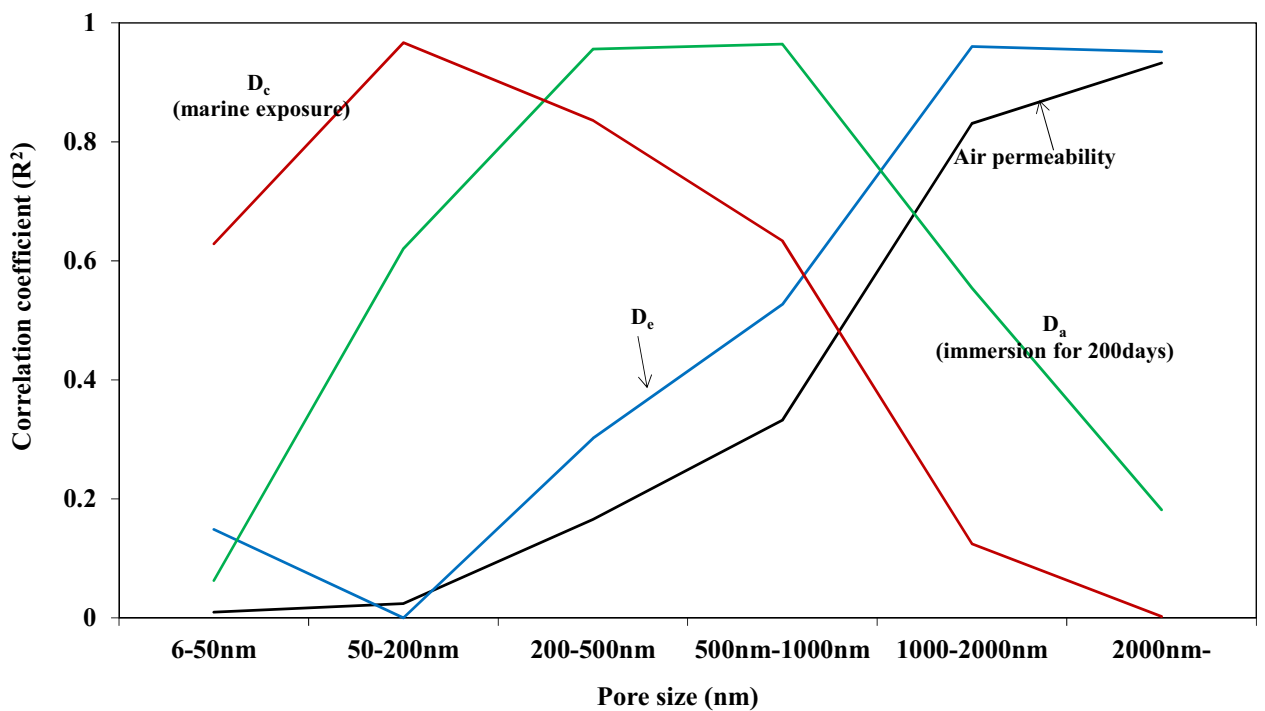

Fig. 12 Correlation coefficient of durability indicators for exposed concrete at different pore sizes.

of chloride ion under the marine condition is greatly affected by the capillary pores of diameter $200 \mathrm{~nm}$ or below due to repeated wet and dry cycles in splash zone and tidal zone. Whereas salt immersion and electrophoretic test specimens are under saturated condition and chloride diffusion becomes predominant. Large pores influence chloride diffusion. Air permeability also is affected by large pores. This is evident from Fig. 12 where correlation coefficients of air permeability and $D_{e}$ tend to increase with increase in pore diameter. Especially, significant correlation is found in pore diameters larger than $1000 \mathrm{~nm}$. Influence of pore diameter on air permeability and $\mathrm{D}_{\mathrm{e}}$ is found to be similar. Therefore they are considered as highly correlated.

Figure 13 shows the correlation coefficients in comparison with pore diameter range for laboratory prepared concretes. The $\mathrm{D}_{\mathrm{a}}$ is highly correlated for pore diameter between $200 \mathrm{~nm}$ and $1000 \mathrm{~nm}$, and correlation coefficient $\left(\mathrm{R}^{2}\right)$ decreased with increasing pore diameter. On the other hand, correlation coefficient $\left(\mathrm{R}^{2}\right)$ for $\mathrm{D}_{\mathrm{e}}$ and air permeability tends to increase with increase in pore diameter in concrete similar to the trend shown in Fig. 12. Especially, effect of pore diameter larger than $1000 \mathrm{~nm}$ is significant.
The trends observed for $\mathrm{D}_{\mathrm{e}}$ and air permeability are similar in both cases of laboratory prepared concrete and concrete exposed to actual marine conditions and therefore they are observed to be highly correlated. The air permeability and effective chloride diffusion coefficient (" $\mathrm{D}_{\mathrm{e}}$ ") by electrophoretic test depend on pore structure. The pore structure of concrete is in turn affected by cement types and curing conditions. Long term exposure to marine conditions can change the pore structure of concrete. However, it is found that the air permeability and effective chloride diffusion by electrophoretic test are correlated. Hence, from the present study, chloride diffusion coefficient can be estimated from the results of air permeability for laboratory prepared concrete and concrete exposed to marine condition, with due consideration to moisture content of concrete.

\section{Conclusions}

An attempt has been made in understanding the relationship between air permeability and durability indicators like neutralization and chloride penetration. Experimental 


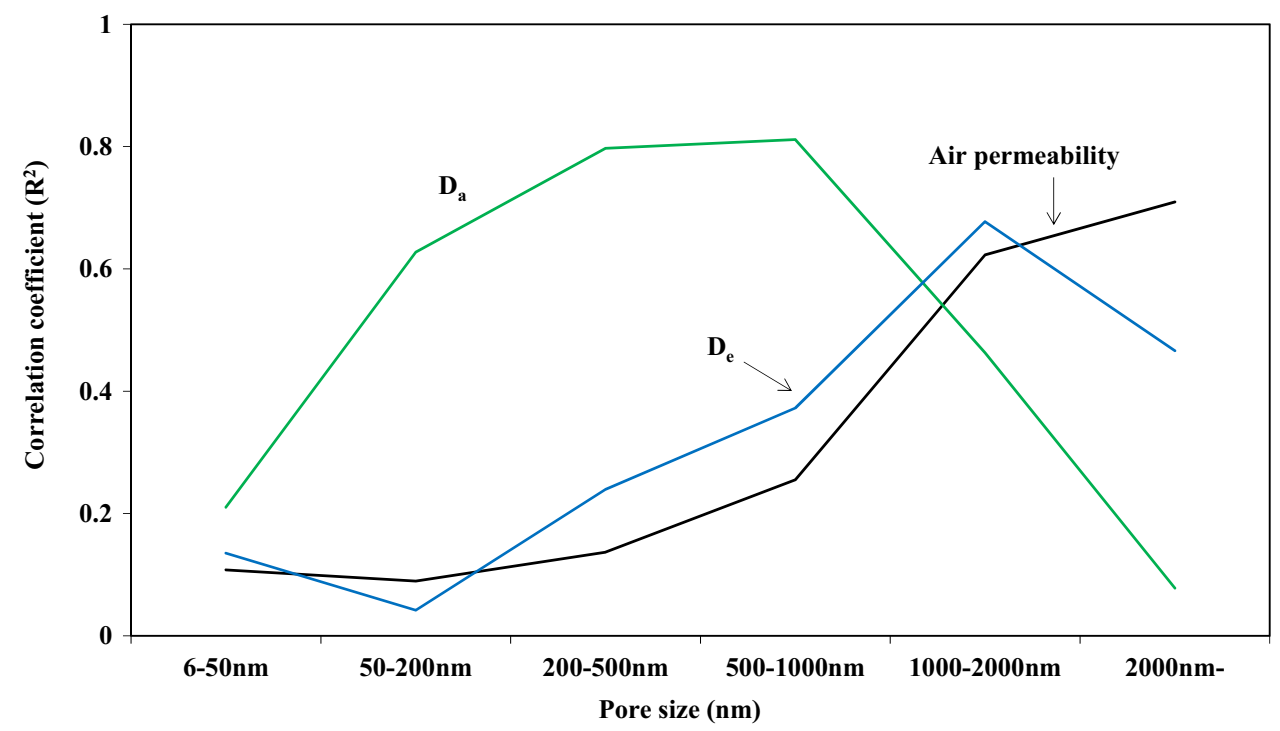

Fig. 13 Correlation coefficient of durability indicators for laboratory prepared concrete at different pore sizes.

investigations are done to elucidate the application of air permeability as an alternative to chloride penetration tests and neutralization tests for both laboratory prepared concrete and for concrete exposed to marine conditions. From the results obtained following conclusions are drawn:

1. Air permeability is highly correlated with water cement ratio, compressive strength and neutralization. Air permeability can be used as an alternative to neutralization coefficient with due consideration to water cement ratio, curing condition and cement type.

2. Air permeability is found to be fairly correlated with chloride diffusion coefficient and the degree of correlation depends on type of tests and curing conditions. When using air permeability as an alternate to chloride diffusion coefficient, cement types and curing conditions plays a significant role.

3. Chloride diffusion by electrophoretic test is better correlated with air permeability than salt immersion test. The estimation of effective diffusion coefficient by air permeability is possible regardless of cement types, but moisture content and curing condition must be taken into account.

4. The apparent chloride ion diffusion coefficient obtained by immersion test of marine exposed concrete samples is affected by pore diameter between 200 and $1000 \mathrm{~nm}$. In the case of wet-dry cyclic condition, smaller pore diameter affects the apparent chloride ion diffusion coefficient for marine exposed concrete. Less correlation is seen between air permeability and diffusion coefficient which is attributed to time-dependent declination of diffusion coefficient due to continued hydration in concrete over longer period.

5. The pore diameter has significant effect on air permeability and chloride ion diffusion coefficient by electrophoretic test, which differ from apparent diffusion chloride ion coefficient, and both are very likely to be affected by the relatively large pore diameter.

6. The air permeability and effective chloride diffusion by electrophoretic test are correlated for laboratory prepared concrete and concrete exposed to marine condition. Hence present study affirms that the chloride diffusion coefficient can be estimated from the results of air permeability with due consideration to moisture content of concrete. This finding provides an experimental tool for assessment of durability.

\section{Open Access}

This article is distributed under the terms of the Creative Commons Attribution 4.0 International License (http:// creativecommons.org/licenses/by/4.0/), which permits unre stricted use, distribution, and reproduction in any medium, provided you give appropriate credit to the original author(s) and the source, provide a link to the Creative Commons license, and indicate if changes were made.

\section{Funding}

This research did not receive any specific grant from funding agencies in the public, commercial, or not-for-profit sectors.

\section{References}

Abbas, A., Carcasses, M., \& Ollivier, J. P. (1999). Gas permeability of concrete in relation to its degree of saturation. Materials and Structures, 32, 3-8.

Al-alaily, H. S., \& Hassan, A. A. A. (2016). Time-dependence of chloride diffusion for concrete containing metakaolin. Journal of Building Engineering, 7, 159-169. 
Al-Amoudi, O. S. B., Al-Kutti, W. A., Ahmad, S., \& Maslehuddin, M. (2009). Correlation between compressive strength and certain durability indices of plain and blended cement concretes. Cement and Concrete Composites, 31, 672-676.

Basheer, L., Kropp, J., \& Cleland, D. J. (2001). Assessment of the durability of concrete from its permeation properties: a review. Construction and Building Materials, 15, 93-103.

Berndt, M. L. (2009). Properties of sustainable concrete containing fly ash, slag and recycled concrete aggregate. Construction and Building Materials, 23, 2606-2613.

Bijen, J. (1996). Benefits of slag and fly ash. Construction and Building Materials, 10(5), 309-314.

Care, S., \& Derkx, F. (2011). Determination of relevant parameters influencing gas permeability of mortars. Construction and Building Materials, 25, 1248-1256.

Costa, A., \& Appleton, J. (1999). Chloride penetration into concrete in marine environment - part I: main parameters affecting chloride penetration. Materials and Structures, 32, 252-259.

Guiglia, M., \& Taliano, M. (2010). Comparison of carbonation depths measured on in-field exposed existing r.c. structures with predictions made using fib-Model Code. Cement and Concrete Composites, 38(2013), 92-108.

Guneyisi, E., Gesoglu, M., Ozturan, T., \& Ozbay, E. (2009). Estimation of chloride permeability of concretes by empirical modeling: considering effects of cement type, curing condition and age. Construction and Building Materials, 23, 469-481.

Halamickova, P., Detwiler, R. J., Bentz, D. P., \& Garboczi, E. J. (1995). Water permeability and chloride ion diffusion in portland cement mortars: relationship to sand content and critical pore diameter. Cement and Concrete Research, 25(4), 790-802.

Hamami, A. A., Turcry, Ph, \& Ait-Mokhtar, A. (2012). Influence of mix proportions on microstructure and gas permeability of cement pastes and mortars. Cement and Concrete Research, 42, 490-498.

Hui-sheng, S., Bi-wan, X., \& Xiao-chen, Z. (2009). Influence of mineral admixtures on compressive strength, gas permeability and carbonation of high performance concrete. Construction and Building Materials, 23, 1980-1985.

Khunthongkeaw, J., Tangtermsirikul, S., \& Leelawat, T. (2006). A study on carbonation depth prediction for fly ash concrete. Construction and Building Materials, 20, 744-753.

Leng, F., Feng, N., \& Lu, X. (2000). An experimental study on the properties of resistance to diffusion of chloride ions of fly ash and blast furnace slag concrete. Cement and Concrete Research, 30, 989-992.

Luping, T., \& Gulikers, J. (2007). On the mathematics of timedependent apparent chloride diffusion coefficient in concrete. Cement and Concrete Research, 37, 589-595.

McCarthy, M. J., \& Dhir, R. K. (2005). Development of high volume fly ash cements for use in concrete construction. Fuel, 84, 1423-1432.

Mu, S., Wu, Y., Jiang, Q., \& Shi, L. (2015). Study on transient air permeability of concrete under different curing conditions. Key Engineering Materials, 629-630, 223-228.
Neves, R., da Fonseca, B. S., Branco, F., de Brito, J., Castela, A., \& Montemor, M. F. (2015). Assessing concrete carbonation resistance through air permeability measurements. Construction and Building Materials, 82, 304-309.

Nielsen, E. P., \& Geiker, M. R. (2003). Chloride diffusion in partially saturated cementitious material. Cement and Concrete Research, 33, 133-138.

Osborne, G. J. (1999). Durability of Portland blast-furnace slag cement concrete. Cement and Concrete Composites, 21, $11-21$.

Pack, S. W., Jung, M. S., Song, H. W., Kim, S. H., \& Ann, K. Y. (2010). Prediction of time dependent chloride transport in concrete structures exposed to a marine environment. $\mathrm{Ce}$ ment and Concrete Research, 40, 302-312.

Papadakis, V. G. (2000). Effect of supplementary cementing materials on concrete resistance against carbonation and chloride ingress. Cement and Concrete Research, 30, 291-299.

Ramezanianpour, A. A., \& Malhotra, V. M. (1995). Effect of curing on the compressive strength, resistance to chlorideion penetration and porosity of concretes incorporating slag, fly ash or silica fume. Cement and Concrete Composites, 17, 125-133.

Saeki, T., Sasaki, K., \& Shinada, K. (2006). Estimation of chloride diffusion coefficient of concrete using mineral admixtures. Journal of Advanced Concrete Technology, 4(3), 385-394.

Salvoldi, B. G., Beushausen, H., \& Alexander, M. G. (2015). Oxygen permeability of concrete and its relation to carbonation. Construction and Building Materials, 85, 30-37.

Sanjuan, M. A., \& Munoz-Martialay, R. (1996). Influence of the water/cement ratio on the air permeability of concrete. Journal of Materials Science, 31, 2829-2832.

Sharif, A., Loughlin, K. F., Azad, A. K., \& Navaz, C. M. (1997). Determination of the effective chloride diffusion coefficient in concrete via a gas diffusion technique. $A C I$ Materials Journal, 94(3), 227-233.

Song, H. W., Lee, C. H., \& Ann, K. Y. (2008). Factors influencing chloride transport in concrete structures exposed to marine environments. Cement and Concrete Composites, 30, 113-121.

Sugiyama, T., Bremner, T. W., \& Tsuji, Y. (1996). Determination of chloride diffusion coefficient and gas permeability of concrete and their relationship. Cement and Concrete Research, 26(5), 781-790.

Takewaka, K., \& Matsumoto, S. (1988). Quality and cover thickness of concrete based on the estimation of chloride penetration in marine environments. Special Publication, 109-17, 381-400.

Tegguer, A.D., Bonnet, S., Khelidj, A., Baroghel-Bouny, V. (2013) Effect of microcraking on gas permeability and chloride diffusion of concrete, VIII, International Conference Fracture Mechanical Concrete \& Concrete Structure. Framcos-8. Spain.

Thomas, M. D. A., \& Bamforth, P. B. (1999). Modelling chloride diffusion in concrete - effect of fly ash and slag. Cement and Concrete Research, 29(3), 487-495. 
Truc, O., Ollivier, J. P., \& Carcassès, M. (2000). A new way for determining the chloride diffusion coefficient in concrete from steady state migration test. Cement and Concrete Research, 30, 217-226.

Villani, C., Loser, R., West, M. J., Bella, C. D., Lura, P., \& Weiss, W. J. (2014). An inter lab comparison of gas transport testing procedures: oxygen permeability and oxygen diffusivity. Cement and Concrete Composites, 53, $357-366$.

Yamaji, T. (2014). Study on the time dependence of chloride ion diffusion in concrete based on exposure test under marine environments. In: Proceedings of the concrete structure scenario (pp. 213-220). Japan: JSMS.
Yang, C. C. (2006). On the relationship between pore structure and chloride diffusivity from accelerated chloride migration test in cement-based materials. Cement and Concrete Research, 36, 1304-1311.

Yildirim, H., Ilica, T., \& Sengul, O. (2011). Effect of cement type on the resistance of concrete against chloride penetration. Construction and Building Materials, 25, 1282-1288.

Zaharieva, R., Buyle-Bodin, F., Skoczylas, F., \& Wirquin, E. (2003). Assessment of the surface permeation properties of recycled aggregate concrete. Cement and Concrete Composites, 25, 223-232. 